\title{
Impacto do Uso da Peer Instruction no Ensino Superior de Lógica para Computação no Brasil
}

\author{
Esdras L. Bispo Jr. \\ bispojr@ufg.br \\ Universidade Federal de Jataí (UFJ) \\ Jataí, Goiás
}

\author{
Rosemara P. Lopes \\ rosemaralopes@gmail.com \\ Universidade Federal de Goiás (UFG) \\ Goiânia, Goiás
}

\begin{abstract}
RESUMO
Um dos desafios da pesquisa na Educação em Computação é a proposição de novos métodos de ensino-aprendizagem. Pesquisas apontam que os métodos de aprendizagem ativa são mais efetivos do que os tradicionais. A Peer Instruction é um destes métodos de aprendizagem que promove uma aula centrada no estudante, possibilitando ele construir a sua compreensão através de uma abordagem estruturada com questões e discussões aos pares, sendo utilizada na Computação nos últimos anos. Todavia, pesquisas sobre o uso deste método são bem escassas na América Sul. Desta forma, o objetivo desta pesquisa é discutir o impacto do uso da Peer Instruction na Educação Superior em Computação no Brasil, no ensino de Lógica para Computação. O contexto da pesquisa é a turma do Bacharelado em Ciência da Computação de 2018.1 da Universidade Federal de Jataí. Foram constatadas evidências suficientes para a veracidade de duas proposições referentes ao estudo: (a) "A utilização da Peer Instruction garante um ganho de aprendizagem dos alunos"; e (b) "A Peer Instruction é bem recebida pelos alunos". Conclui-se que o uso da Peer Instruction é adequada para a Educação Superior em Computação no Brasil, havendo boa receptividade dos estudantes.
\end{abstract}

\section{CCS CONCEPTS}

\section{- Social and professional topics $\rightarrow$ Computing education.}

\section{PALAVRAS-CHAVE}

educação; computação; lógica; peer instruction, Brasil

\section{INTRODUÇÃO}

Um excelente ponto de partida para descrever a Pesquisa em Educação de Computação (PEC) são as duas áreas de sua junção: a Educação e a Ciência da Computação. Pode-se definir, como um dos objetivos principais da PEC, o aperfeiçoamento do processo de ensino e aprendizagem da Computação como ciência [16].

Existem muitos desafios abertos na PEC [30]. Um dos desafios constantes da PEC é proposição de novos métodos de ensino [10]. Muitos trabalhos apontam que os métodos de aprendizagem ativa são mais efetivos do que os métodos tradicionais de ensino $[5,12]$.

Fica permitido ao(s) autor(es) ou a terceiros a reprodução ou distribuição, em parte ou no todo, do material extraído dessa obra, de forma verbatim, adaptada ou remixada, bem como a criação ou produção a partir do conteúdo dessa obra, para fins não comerciais, desde que sejam atribuídos os devidos créditos à criação original, sob os termos da licença CC BY-NC 4.0.

EduComp'21, Abril 27-30, 2021, Jataí, Goiás, Brasil (On-line)

(c) 2021 Copyright mantido pelo(s) autor(es). Direitos de publicação licenciados à Sociedade Brasileira de Computação (SBC)
Podemos citar como métodos de aprendizagem ativa a (i) Aprendizagem Colaborativa [4], a (ii) Aprendizagem guiada por Indagações [22], e a (iii) Peer Instruction (PI).

A PI é um método de ensino que promove uma aula centrada no estudante, de forma que ele possa construir a sua compreensão através de uma abordagem estruturada com questões e discussões aos pares [8]. Embora primeiramente utilizada em disciplinas da Física, outros cursos também estão utilizando a PI (e.g. Biologia [36]). Vários trabalhos discutem o impacto do uso da PI na Educação de Computação [6, 17, 19, 27, 29, 33, 34, 41, 42].

Uma das direções interessantes que a PI na Educação de Computação está seguindo é a criação de métricas para medir a qualidade da aprendizagem $[28,35]$. Perguntas como (i) "existe na realidade uma aprendizagem efetiva do estudante?", ou (ii) "o estudante concorda de forma passiva com seus colegas?" são endereçadas.

Todavia, pesquisas sobre o uso da PI são bem escassas na América Sul [23]. Desta forma, o objetivo desta pesquisa é discutir o impacto do uso da PI na Educação Superior de Computação no Brasil no ensino de Lógica para Computação. Duas questões de investigação norteiam esta pesquisa: (i) a utilização da PI é adequada para a Educação de Computação no Brasil?; e (ii) a PI é bem recebida pelos alunos? Esta última questão é particularmente importante pois ainda parece haver uma resistência pela adoção de metodologias ativas por parte de estudantes de exatas [32]. O contexto da pesquisa é a turma do Bacharelado em Ciência da Computação de 2018.1 da Universidade Federal de Jataí.

O restante do trabalho é dividido como se segue. A Seção 2 apresenta conceitos importantes sobre Educação. A Seção 3 descreve a metodologia de Peer Instruction. A Seção 4 detalha algumas métricas utilizadas para se avaliar os ganhos de aprendizagem em PI. A Seção 5 delinea a metodologia de pesquisa utilizada neste trabalho. A Seção 6 apresenta a discussão dos resultados do estudo de caso, elencando as evidências descobertas. E, por fim, os trabalhos relacionados (Seção 7) e as considerações finais (Seção 8) são apresentados.

\section{FUNDAMENTOS EM EDUCAÇÃO}

\subsection{Ensino Tradicional}

Descrever a abordagem do processo de ensino-aprendizagem tradicional não é uma tarefa fácil. Primeiramente porque na maior parte das vezes ela é referenciada como uma perspectiva antagônica (e por vezes negativa) às demais abordagens, i.e, ela serve como referência para muitas abordagens sobre "como não conduzir" o processo de ensino-aprendizagem.

E, em segundo lugar, como consequência da primeira justificativa, os adeptos e praticantes desta abordagem não costumam fazer 
esta auto-denominação (no sentido negativo do termo "tradicional”). Da mesma forma que a diferenciação explícita sobre o que é sagrado, e o que não é sagrado, normalmente é feita por adeptos de um determinado grupo religioso; a distinção entre a prática tradicional e as demais práticas são estabelecidas mais comumente por discordantes de tal abordagem. Quem propõe algo novo, distinto das práticas vigentes, são quem normalmente necessitam de nomenclaturas específicas para realizar uma distinção mais clara.

Embora as dificuldades existam para caracterizar a abordagem tradicional, fazê-la é preciso. Se há a necessidade de repensar o fazer docente, logo é necessário identificar quais elementos deste fazer estão sendo apontados como desafios para serem confrontados e superados. Mizukami [21] aponta alguns elementos importantes nesta direção. Dois desses elementos são sobre a concepção de: (i) ser humano, e da (ii) relação professor-aluno.

Sobre a concepção de ser humano, o ensino tradicional normalmente admite a compreensão do mundo deste inicialmente como uma "tábula rasa" em que vai recebendo gradualmente o conhecimento que é adquirido pelo ambiente. Este ser humano não tem discernimento inicial sobre o que é útil para o seu próprio aprendizado, sendo fundamental a recepção desse conhecimento pelos mais antigos. Diz a autora que este ser humano "é um receptor passivo até que, repleto das informações necessárias, pode repeti-las a outros que ainda não as possuem”. Os mais antigos também são os que determinam o que deve ser aprendido pelos seres noviços.

Sobre a relação professor-aluno, normalmente admite-se que o professor tem a posse do conhecimento do qual o aluno necessita aprender. Cabe ao professor estabelecer metodologia, conteúdo, avaliação e forma de interação na sala de aula. Estes aspectos do processo de ensino-aprendizagem são de total responsabilidade do professor, sendo o aluno alheio a esta parte do processo. Uma vez que o aluno é tido como receptor passivo, a função do professor é transmitir certos conteúdos considerados apropriados para este aluno. Diz ainda a autora que esta é uma relação "[...] vertical, sendo que um dos polos (o professor) detém o poder decisório".

A partir desta caracterização, concepções distintas sobre como deveria ser o processo de ensino-aprendizagem foram propostas como alternativa à abordagem tradicional. Em contraposição principalmente à concepção do aluno como "receptor passivo", surge a teoria da aprendizagem ativa.

\subsection{Teoria da Aprendizagem Ativa}

A teoria da aprendizagem ativa enfatiza a necessidade do engajamento dos estudantes durante o seu processo de aprendizado. Não há uma definição clara sobre a aprendizagem ativa, mas indiretamente alguns autores a mencionaram em seus escritos como uma atividade inerente do estudante. Por exemplo, Dewey [9] afirma que a aprendizagem é "[...] algo que um indivíduo faz quando ele estuda. É uma empreitada ativa e conduzida pessoalmente”. Bonwel e Eison [5] afirmam que a aprendizagem é ativa quando há uma "ênfase maior [...] na exploração dos estudantes de suas próprias atitudes e valores".

É necessário ressaltar que é possível existir uma aprendizagem ativa mesmo em aulas em formato expositivo. Embora o ambiente no qual o aluno se encontre determina significativamente as condições para o seu aprendizado, ele não o determina por completo. Em uma aula expositiva, o estudante pode estar ativamente considerando cada informação e argumentos que estão sendo apresentados, reorganizando, filtrando e reconstruindo as novas informações recebidas a partir do conhecimento prévio por ele já apropriado.

Entretanto, tendo em vista que as aulas em formato expositivo estão fortemente associadas às concepções de ensino tradicional vigentes, têm-se repensado o papel da aula expositiva dentro dos espaços de educação formal, inclusive no ensino superior. Algumas metodologias propõem uma participação mais efetiva do aluno dentro da sala de aula, com o objetivo de promover ambientes que potencializem mais concretamente cenários de aprendizagem ativa.

O ensino pela descoberta, por exemplo, refere-se a uma forma de currículo em que os estudantes são expostos a questões e experiências específicas de forma que eles "descubram por si mesmos" os conceitos esperados pelo professor [15]. Esta abordagem empenha esforços em integrar a necessidade de atender às expectativas de cumprimento de um programa de conteúdo com a configuração de um ambiente favorável ao questionamento investigativo dos alunos. O ensino pela descoberta adota a teoria da aprendizagem ativa e é uma alternativa ao ensino tradicional.

Apesar do esforço apresentar bons resultados [3], ainda existem dificuldades com a implantação do ensino pela descoberta. A tensão entre "cobrir o conteúdo" e a investigação científica é uma destas dificuldades [14]. Enquanto que o conhecimento do conteúdo é bastante exigido pelo ensino tradicional, o ensino pela descoberta deposita maior ênfase no desenvolvimento das habilidades necessárias durante o processo de experimentação daquele conteúdo.

Diante deste cenário de tensão, pesquisas na área da Psicologia contribui para uma melhor justificativa da aprendizagem ativa. Um destes campos é a Psicologia Cognitiva que é "o estudo de como as pessoas percebem as informações, aprendem-nas, lembram-se delas e pensam nelas" [37]. Ao contrário de outras áreas da psicologia, ela procura teorizar mais fortemente sobre os mecanismos de funcionamento das estruturas cognitivas de um indivíduo. Outras áreas da psicologia podem ter interesse maior, por exemplo, nos aspectos comportamentais dos indivíduos, ao invés dos processos internos de estruturação das informações assimiladas.

Dentro desta área, Ausubel [2] propôs a teoria da assimilação da aprendizagem e retenção significativas ou, como é simplesmente conhecida, teoria da aprendizagem significativa (TAS).

A TAS afirma que a aprendizagem de recepção significativa envolve a aquisição de novos conhecimentos a partir de um material de aprendizagem apresentado. Entretanto, é pressuposto, além da existência deste material, um conjunto de elementos essenciais para que a aprendizagem significativa ocorra.

Alguns destes elementos são melhor identificados através da descrição dos processos de assimilação na fase de aprendizagem significativa. Três etapas desta fase são de fundamental importância para a TAS. A primeira é a ancoragem seletiva do material de aprendizagem às ideias existentes na estrutura cognitiva. A segunda é a interação das ideias novas que estão sendo introduzidas com as ideias relevantes já existentes; o significado das novas ideias emergem como produto da interação com as ideias preexistentes. E, por fim, a terceira é a ligação na memória (retenção) dos novos significados emergentes com as suas ideias-âncoras correspondentes.

Tendo como um dos propósitos a conciliação entre o ensino expositivo e o ensino pela descoberta, a metodologia da Peer Instruction 
foi proposta. Esta metodologia busca operacionalizar uma prática que considera o formato tradicional de sala de aula, alterando-o com espaços que possibilitem um engajamento maior por parte dos estudantes na construção do seu aprendizado.

\section{METODOLOGIA DE PEER INSTRUCTION}

A metodologia de Peer Instruction ${ }^{1}$ (PI) foi originalmente proposta pelo Prof. Eric Mazur da Universidade de Harvard. De um modo geral, a PI busca promover a aprendizagem com foco no questionamento com o intuito de os alunos dedicarem mais tempo em classe refletindo e discutindo o conteúdo em si, do que "passivamente assistindo exposições orais por parte do professor" [1].

Os objetivos básicos da PI são explorar a interação do estudante durante a aula e focar a sua atenção aos conceitos subjacentes. Ao invés de utilizar a aula para apresentar o material a ser aprendido no nível de detalhamento presente no livro-texto, as aulas consistem principalmente de apresentações curtas dos pontos-chaves. Depois destas pequenas explanações, uma questão conceitual é apresentada com o propósito de ser respondida e discutida pelos estudantes. Este processo (i) força os estudantes a pensarem através dos argumentos que eles mesmos estão desenvolvendo, e (ii) fornece para eles mesmos o recurso para aferir a sua compreensão sobre o conceito.

A PI é um método de ensino que consiste em dois grandes momentos: um momento individual e um momento em grupo. $\mathrm{O}$ momento individual é baseado no estudo prévio de materiais disponibilizados pelo professor aos alunos. Este momento é imprescindível para que a dinâmica proposta posteriormente alcance a sua eficácia. $\mathrm{O}$ propósito é que o momento em grupo seja melhor utilizado com atividades que potencialize a aprendizagem em parceria com os colegas e com o professor.

Entende-se assim que o estudo prévio é o momento ideal para o estudante ter o primeiro contato com o material, reconhecendo e desenvolvendo parte do conhecimento necessário. É também neste momento que surgem eventuais dúvidas, gerando assim uma maior necessidade do aluno de compreender o assunto.

Cada etapa deste processo será descrita em mais detalhes a seguir. O processo inicia com uma exposição dialogada realizada pelo professor. Esta exposição dialogada deve ser breve, com o intuito de apenas recapitular sucintamente o material já disponibilizado aos alunos previamente. Recomenda-se não passar de mais de 15 minutos nesta etapa.

Na segunda etapa, uma questão conceitual é apresentada para a turma. Esta questão normalmente é de múltipla escolha. Cada aluno deve respondê-la individualmente. O objetivo da questão conceitual é promover e avaliar a compreensão dos estudantes sobre os conceitos mais importantes escolhidos para aquele momento.

$\mathrm{Na}$ terceira etapa, o registro das respostas individuais dos estudantes é realizado. Quando se utiliza questões de múltiplas escolhas, é possível gerar o histograma das respostas fornecidas pelos estudantes. A partir da porcentagem de acertos da turma referente àquela questão conceitual, segue-se o seguinte fluxo:

- sendo maior que $70 \%$, admite-se que a turma compreendeu satisfatoriamente o conceito exigido. Logo, ou passa-se para uma nova questão envolvendo o mesmo conceito ou segue-se para a exposição breve de um novo conceito;

\footnotetext{
${ }^{1}$ Também chamada de Instrução pelos colegas (IpC).
}

- estando entre $30 \%$ e $70 \%$, admite-se que uma parte da turma compreende satisfatoriamente o conceito e pode colaborar no processo de construção do conhecimento de seus pares. Também se é admitido que a discussão entre os pares põe à prova o suposto conhecimento obtido pela parte da turma que respondeu corretamente à questão. Logo é solicitado que os alunos dividam-se em grupos e destinem um tempo para convencer os seus pares das razões de terem respondido de uma certa maneira ou de outra;

- sendo menor que 30\%, admite-se que a turma não compreendeu satisfatoriamente o conceito exigido. Logo, o professor revisita o conceito, começando novamente o processo.

Por fim, a quarta etapa compreende ao registro da votação logo após a discussão entre os colegas. Esta etapa só ocorre se, na primeira votação, a porcentagem de acertos situar entre 30\% e 70\%. O novo histograma é gerado e o professor encerra esta fase fazendo a explanação da questão e dos aspectos conceituais abordados. Se ainda for necessário desenvolver o conceito atual, uma nova questão referente a este é apresentada. Caso contrário, um próximo tópico, com novos conceitos é apresentado via exposição dialogada.

Existem diversas variantes do método PI. Algumas vão omitir as votações de algumas etapas. Outras obrigatoriamente vão realizar a discussão entre os colegas (independente da porcentagem de acertos registrada). Porém, a sugestão original proposta por Mazur [20] é enumerada a seguir:

(1) Apresentação da questão conceitual ( $\cong 1$ minuto);

(2) Ponderação dos estudantes sobre a questão ( $\cong 1$ minuto);

(3) Registro das respostas individuais dos estudantes (opcional);

(4) Discussão entre os colegas ( $\cong 1$ minuto);

(5) Registro das respostas individuais pós-discussão (opcional);

(6) Retorno do professor: contagem das respostas;

(7) Explanação da resposta correta ( $\cong 2$ minutos ou mais).

\section{MÉTRICAS NA PI}

A PI foi largamente adotada em vários contextos educacionais [39]. Com isto, surgiu a necessidade de mensurar com melhor acurácia a eficácia da PI na aprendizagem dos alunos. Será apresentada a seguir o conceito de questões isomórficas e duas métricas utilizadas para aferir o ganho de aprendizagem dos alunos utilizando a PI.

\subsection{Questões Isomórficas}

Uma das estratégias adotadas para se responder algumas das dúvidas sobre a eficácia da PI é o uso de questões isomórficas, conforme apresentada brevemente por Smith e colegas [35]. Questões isomórficas têm "histórias diferentes", mas exigem a aplicação dos mesmos princípios ou conceitos para se obter a solução.

A proposta de utilizar questões isomórficas em PI por Smith e colegas é uma apropriação do conceito de problema-isomorfos [18]. Os problemas-isomorfos não podem ser diferentes na estrutura do problema. As diferenças entre eles residem nas personagens, imagens ou modelos utilizados nos problemas. A ideia é realizar uma mudança na representação do problema, preservando a estrutura do domínio da tarefa em questão.

Neste trabalho, um par de questão isomórficas é definido como $\left(q_{1}, q_{2}\right)$, em que $q_{1}$ e $q_{2}$ são questões conceituais de múltipla escolha. 
$q_{1 d d}$ refere-se à reapresentação de $q_{1}$ depois da discussão pelos colegas.

\subsection{Ganho de Aprendizagem Absoluta}

Com o propósito de definir o ganho de aprendizagem absoluta, serão apresentadas a seguir as funções 1,2 e 3 :

$$
\operatorname{Acerta}(x, q)= \begin{cases}1, & \text { se } x \text { acerta } q, \\ 0, & \text { caso contrário. }\end{cases}
$$

em que $x$ é um estudante respondendo à questão $q$;

$$
\operatorname{MediaCorretas}(q)=\frac{\sum_{x \in T} \operatorname{Acerta}(x, q)}{n}
$$

em que $T$ é uma turma de $n$ estudantes; e

$$
\operatorname{PctMedia}_{\text {Cor }}(Q)=\frac{\sum_{q \in Q} \operatorname{MediaCorretas}(q)}{m}
$$

em que $Q$ é um conjunto de $m$ perguntas.

Pode-se definir ainda $I=\left\{\left(q_{1}^{1}, q_{2}^{1}\right) ;\left(q_{1}^{2}, q_{2}^{2}\right) ; \ldots ;\left(q_{1}^{m}, q_{2}^{m}\right)\right\}$ como o conjunto de todos os pares de questões isomórficas. Define-se $Q_{1}$ e $Q_{2}$, a partir de $I$, de forma que $Q_{1}=\left\{q_{1}^{1}, q_{1}^{2}, \ldots, q_{1}^{m}\right\}$ e $Q_{2}=$ $\left\{q_{2}^{1}, q_{2}^{2}, \ldots, q_{2}^{m}\right\}$. Assim, define-se o ganho de aprendizagem absoluta (GAA) como se segue:

$$
G A A=\operatorname{PctMedia}_{\mathrm{Cor}}\left(Q_{2}\right)-\operatorname{PctMedia}_{\mathrm{Cor}}\left(Q_{1}\right)
$$

A ideia subjacente desta métrica é aferir o ganho de aprendizagem após uma dada intervenção. Suponha que uma turma obteve $51 \%$ de acerto no conjunto $Q_{1}$ e, após a discussão em grupos, obteve $72 \%$ de acertos no conjunto $Q_{2}$. Logo, seu GAA seria $21 \%$.

\subsection{Ganho de Aprendizagem Normalizado}

O ganho de aprendizado normalizado (GAN) [13, p. 3] fornece uma medida de como o desempenho do estudante cresce, se comparado com o maior crescimento possível que ele possa obter. O GAN é calculado como se segue:

$$
G A N=\frac{\operatorname{PctMedia}_{\mathrm{Cor}}\left(Q_{2}\right)-\operatorname{PctMedia}_{\mathrm{Cor}}\left(Q_{1}\right)}{100 \%-\operatorname{Pct} \text { Media }{ }_{\mathrm{Cor}}\left(Q_{1}\right)}
$$

No exemplo dado na seção anterior, enquanto que o GAA seria $21 \%$, o GAN seria $(72 \%-51 \%) /(100 \%-51 \%) \cong 42,86 \%$. Assim, de todo o ganho de aprendizagem restante disponível, aproximadamente $42,86 \%$ foi obtido através da intervenção.

Um outro exemplo pode ser mais ilustrativo. Imagine dois cenários em que o GAA é de $10 \%$ para duas turmas $A$ e $B$ quaisquer. Entretanto, a turma $A$ tem $\operatorname{PctMedia}$ Cor $\left(Q_{1}\right)=20 \%$ e PctMedia $\operatorname{Cor}_{2}\left(Q_{2}\right)=$ $30 \%$, enquanto que a turma $B$ tem PctMedia ${ }_{\text {Cor }}\left(Q_{1}\right)=80 \%$ e Pct Mediacor $\left(Q_{2}\right)=90 \%$. Ora, deve ser bem mais difícil obter um GAA de $10 \%$ quando se parte de $80 \%$ do que quando se parte de $20 \%$. O GAN tem por objetivo medir esta dificuldade relativa, de forma que o $G A N_{A}=12,5 \%$ e o $G A N_{B}=50,0 \%$.

\subsection{Ganho de Aprendizagem Ponderado}

Em [35], um diagrama com as porcentagens média de respostas corretas e incorretas de questões conceituais foi apresentado ( $\mathrm{Fi}$ gura 1). O propósito deste diagrama é auxiliar na mensuração do ganho de aprendizagem dos estudantes ao utilizar a discussão em grupos. O diagrama é dividido em três níveis que correspondem às porcentagens referentes aos conjuntos $Q_{1}, Q_{1 d d}$ e $Q_{2}$.

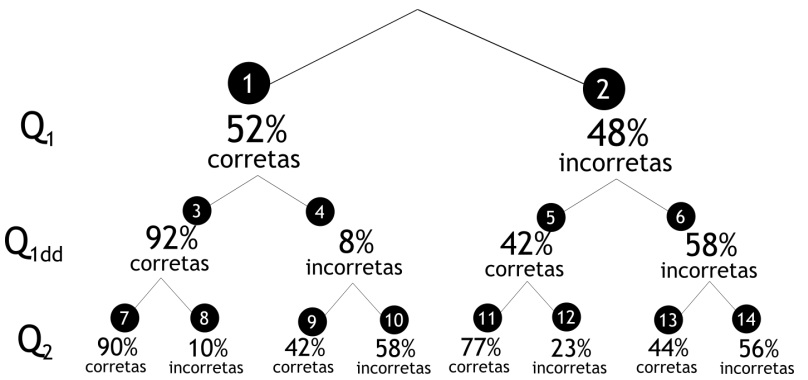

Figura 1: Diagrama com as porcentagens média de respostas corretas e incorretas dos conjuntos de questões $Q_{1}, Q_{1 d d}$ e $Q_{2}$ em [35].

Os Nós 1 e 2 da Figura 1 são porcentagens referentes às respostas do conjunto $Q_{1}$. O Nó 1 corresponde à porcentagem média de respostas corretas, enquanto que o Nó 2 corresponde à porcentagem média de respostas incorretas.

Os Nós 3 e 4 são porcentagens referentes às respostas do conjunto $Q_{1 d d}$, porém somente com os estudantes que responderam corretamente $q_{1}$ (Nó 1). O Nó 3 corresponde à porcentagem média de respostas corretas, enquanto que o Nó 4 corresponde à porcentagem média de respostas incorretas. A soma das porcentagens do Nó 3 e 4 é $100 \%$ e corresponde à totalidade referente ao Nó 1.

O mesmo acontece com os Nós 5 e 6. Estes nós são porcentagens referentes às respostas do conjunto $Q_{1 d d}$, porém agora somente com os estudantes que responderam incorretamente $q_{1}$ (Nó 2). O Nó 5 corresponde à porcentagem média de respostas corretas, enquanto que o Nó 6 corresponde à porcentagem média de respostas incorretas. A soma das porcentagens do Nó 5 e 6 resultam em $100 \%$ e correspondem a totalidade referente ao Nó 2. A lógica segue-se também para os demais nós da Figura 1.

Para Smith e colegas, alguns nós da Figura 1 auxiliam na identificação de ganho de aprendizagem através do uso do PI. Por exemplo, o Nó 11 indica um considerável ganho de aprendizagem. Os estudantes associados a este nó são aqueles que responderam incorretamente $Q_{1}$ (Nó 2) e, após a discussão com os colegas, responderam corretamente $Q_{1}$ (Nó 5). Destes estudantes, $77 \%$ responderam corretamente $Q_{2}$, indicando possivelmente o efeito positivo da discussão com os colegas no processo de aprendizagem.

Porter e colegas [28] utilizaram a PI em duas disciplinas da Ciência da Computação: Introdução à Teoria da Computação e Arquitetura de Computadores. Entretanto, alguns dos resultados esperados não foram encontrados. Desta forma, foi proposta uma compreensão auxiliar para complementar a leitura inicialmente proposta em [35]. Dois grupos são propostos: um grupo de controle (GC) e um grupo de teste, de aprendizes em potencial (GT). O GC são aqueles que responderam corretamente tanto $q_{1}$ quanto $q_{1 d d}$ (Nó 3). O GT são aqueles que supostamente aprenderam o conceito através da discussão pelos colegas (Nó 5).

A ideia é utilizar a habilidade do GC responder corretamente $q_{2}$ para auxiliar na normalização das expectativas para o GT responder 
corretamente $q_{2}$. Assim, se o GC não responder satisfatoriamente $Q_{2}$, deveria-se ponderar as expectativas em relação ao GT. Desta forma, o ganho de aprendizagem ponderado (GAP) é definido como:

$$
G A P=\frac{\text { PctMedia }_{\text {Cor }}(G T)}{\text { PctMedia }_{\text {Cor }}(G C)}
$$

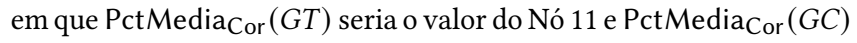
seria o valor do Nó 7 . Desta forma, na Figura 1, o GAP seria $42 \% / 92 \% \cong$ $46 \%$, revelando que o ganho de aprendizado do GP foi aproximadamente $46 \%$ do ganho que o GC obteve.

Quanto mais próximo de $100 \%$ o GAP for, mais significativo é o ganho de aprendizagem alcançado pelo GT. A princípio, o GAP não deveria atingir valores maiores do que $100 \%$. Entretanto, esta possibilidade não é descartada na prática. Assim, uma vez isto ocorrendo, é necessária uma reflexão mais aprofundada de quais cenários e o por quê de o GC obter um ganho de aprendizagem inferior ao ganho do GP.

\section{METODOLOGIA}

Um estudo de caso é uma investigação empírica que investiga um fenômeno contemporâneo dentro de seu contexto da vida real, especialmente quando os limites entre o fenômeno e o contexto não estão claramente definidos [40]. Esta investigação enfrenta uma situação tecnicamente única em que haverá muito mais variáveis de interesse do que ponto de dados, e, como resultado, (i) baseia-se em várias fontes de evidências, com os dados precisando convergir em um formato de triângulo, e, como outro resultado, (ii) beneficia-se do desenvolvimento prévio de proposições teóricas para conduzir a coleta e análise de dados.

\subsection{Elementos Gerais do Estudo de Caso}

Este é um estudo de caso único holístico, utilizando uma estratégia explanatória. A justificativa deste estudo reside no caso revelador que é a utilização da PI na Educação Superior de Computação no Brasil. Os estudos do levantamento bibliográfico concentram-se principalmente em países da América do Norte e Europa [23].

Duas questões de estudo são elencadas. A primeira questão (QEC.1) é "Por que a utilização da PI é adequada para a Educação de Computação no Brasil?”. E a segunda questão (QEC.2) é “Como são as impressões dos estudantes em relação à PI?".

Duas proposições são postas com o propósito de serem investigadas. A primeira proposição (P1) é "A utilização da PI garante um ganho de aprendizagem dos alunos”. A segunda proposição (P2) é "A PI é bem recebida pelos alunos". A resposta de QEC.1 depende diretamente de P1 e P2 serem confirmadas; e a resposta de QEC.2 depende diretamente da investigação de $\mathrm{P} 2$.

A unidade de análise do estudo é a turma de Lógica para Ciência de Computação do Bacharelado em Ciência da Computação da Universidade Federal de Jataí, localizada no sudoeste goiano. A ministração da disciplina ocorreu primeiro semestre de 2018, com a participação de 44 estudantes.

\subsection{Coleta de Dados}

Os dados coletados vieram de três fontes, a saber: o registro das respostas realizadas pelos estudantes durante as aulas (D1); e dois questionários sobre as impressões dos estudantes, sendo o primeiro com questões fechadas (D2), e o segundo com questões abertas (D3).
$\mathrm{O}$ registro das respostas dos estudantes foram feitos durante todo o semestre. Foram utilizadas placas no formato QR Code que associavam cada aluno às suas respectivas respostas em cada questão. A plataforma Plickers $^{2}$ foi utilizada com o propósito de coletar as respostas durante às aulas, calcular o percentual de acertos em tempo real e organizar as respostas em uma planilha eletrônica para as análises futuras. Foram utilizadas ao todo 35 questões, sendo que dentre estas, 06 pares de questões isomórficas.

O primeiro questionário sobre as impressões dos estudantes, através de perguntas fechadas, foi adaptado de [19, p. 18]. Cada pergunta exigia um grau de consentimento da asserção apresentada, optando por uma das cinco respostas em uma escala do tipo Likert [24], variando de "Discordo Totalmente" até "Concordo Totalmente". As asserções do primeiro questionário são listadas a seguir.

[QT1.1] O nível de dificuldade do material proposto nos estudos prévios foram satisfatórios para mim.

[QT1.2] Pensar sozinho sobre as questões apresentadas em sala de aula, antes de discutir com os meus colegas, ajudoume a aprender sobre o material exigido no estudo prévio.

[QT1.3] Discutir sobre o assunto com os meus colegas em sala ajudou-me a compreender melhor o material exigido no estudo prévio.

[QT1.4] O retorno imediato da votação ajudou-me a focar nas fragilidades da minha compreensão sobre o material da disciplina.

[QT1.5] As placas (QR Code), utilizadas para a realização da votação, são ferramentas de colaboração fáceis de usar.

[QT1.6] Eu recomendo que outros professores utilizassem esta abordagem (estudo prévio, questões conceituais, votações, discussão em grupo) em suas disciplinas.

Além da tradução dos enunciados das asserções, houve apenas duas adaptações ao questionário original. A primeira adaptação foi a modificação da questão [QT1.5] em que ao invés de "clickers" foi substituída por "placas (QR Codes)". A segunda modificação foi a inclusão da questão [QT1.1] que foi provocada por uma ligeira suspeição do professor sobre a adequabilidade (ou não) do material de leitura proposto.

O segundo questionário sobre as impressões dos estudantes, através de questões abertas, foi adaptado de [20, p. 21]. As perguntas do segundo questionário são listadas a seguir.

[QT2.1] O que mais você gostou neste formato de aula? [QT2.2] O que mais você detestou neste formato de aula? [QT2.3] Se você fosse ministrar as aulas desta disciplina, o que você faria?

[QT2.4] Se você pudesse mudar alguma coisa no formato desta aula, o que você mudaria?

[QT2.5] Há mais algum comentário ou observação que queira registrar em relação à Peer Instruction?

Além da tradução das perguntas, houve apenas uma adaptação do questionário original. Foi incluída a questão [QT2.5] que teve o propósito de coletar outras eventuais impressões que poderiam surgir do estudante.

Todos os dois questionários foram aplicados depois do encerramento do semestre letivo, via ferramenta online.

\footnotetext{
${ }^{2}<$ http://www.plickers.com>
} 


\subsection{Análise de Dados}

Há uma vinculação entre os dados e às proposições que foram investigadas. Os dados em D1 forneceram suporte à proposição $\mathrm{P} 1$ através das métricas de GAA, GAN e GAP (ver Seção 4). Os dados em D2 e em D3 forneceram suporte às proposições P1 e P2 através da triangulação das respostas dos dois questionários.

Três critérios foram utilizados para interpretar as descobertas obtidas. O primeiro critério $(\mathrm{C} 1)$ é de caráter quantitativo e será considerado satisfatório se: (i) GAA $\geq 10 \%$; (ii) GAN $\geq 20 \%$, e (iii) $\mathrm{GAP} \geq 70 \%$. C1 está diretamente associado à $\mathrm{P} 1$.

$\mathrm{O}$ segundo critério $(\mathrm{C} 2)$ é de caráter quali-quantitativo e contrasta, por meio da triangulação, o resultados dos dois questionários aplicados. Propõe-se um índice de representatividade para as respostas coletadas em D2, conforme definida a seguir:

$$
\operatorname{IndRep}(P)=\frac{\sum_{x \in T} \operatorname{Resposta}(x, P)}{n}
$$

em que $\operatorname{Resposta}(x, P)$ tem valores associados de 0 a 1 , de forma que (i) quando $x$ responde $P$ com "Discordo Totalmente", o valor é 0 , e (ii) quando $x$ responde $P$ com "Concordo Totalmente", o valor é 1. As demais respostas têm valores linearmente proporcionais entre estes dois valores. $\mathrm{O}$ índice de representatividade indica o valor médio das respostas da turma ( $n$ alunos) para uma dada pergunta $P$ em D2. A turma irá tender a "discordar totalmente" da asserção de $P$, se o índice tender ao valor 0 ; e irá tender a "concordar totalmente", se o índice tender ao valor 1 .

Cada pergunta no questionário D2, será comparado com as impressões expressas em texto livre em D3. É considerado satisfatório se, para todas as perguntas em D2, o seu índice de representatividade for maior do que 70\%; e os resultados em D3 forem coerentes com os resultados em D2. C2 está diretamente associado a P1 e P2.

O terceiro critério (C3) é de caráter qualitativo. É considerado satisfatório se evidências forem encontradas em D3 de forma que sejam respaldadas pelos dados coletados em D1 e em D2. C3 está diretamente associado a P1 e P2.

Desta forma, atendendo aos três critérios, compreende-se que é possível realizar uma generalização analítica, estendendo as hipóteses do estudo para o recorte proposto.

\section{DISCUSSÃO DOS RESULTADOS}

Serão apresentadas, a seguir, as evidências descobertas a partir da análise dos dados coletados durante o estudo de caso. As evidências foram divididas de forma a sustentar a Proposição P1 (Seção 6.1) e a Proposição P2 (Seção 6.2).

\subsection{Ganho de Aprendizagem (P1)}

A P1 afirma que a utilização da PI garante um ganho de aprendizagem dos alunos. A seguir, iremos trazer os resultados da investigação de tal afirmação.

Evidência 1: O ganho de aprendizagem é constatado pelos GAA, GAN e GAP.

Constata-se, a partir da análise dos dados D1, que o ganho de aprendizagem ocorre através do valores do GAA, GAN e GAP. Conforme $C_{1}$, o GAA e o GAN são satisfatórios. O valor do GAA é $62 \%-49 \%=13 \%$, sendo maior do que $10 \%$. E o valor do GAN é $(62 \%-49 \%) /(100 \%-49 \%) \cong 25,50 \%$, sendo maior do que $20 \%$. Tem-se com isto que o GAA próximo de $10 \%$ é correspondente a um ganho de aproximadamente $25 \%$, referente a todo o ganho possível. Logo houve um ganho correspondente a mais de um quarto do máximo possível.

Ainda conforme $C_{1}$, o GAP também é satisfatório. A Figura 2 sumariza as porcentagens média das respostas corretas e incorretas do caso. O valor do GAP é $51 \% / 71 \% \cong 71,83 \%$, sendo maior do que $70 \%$. Logo, o GT conseguiu um ganho de aprendizagem correspondente a aproximadamente $72 \%$ do ganho obtido pelo GC.

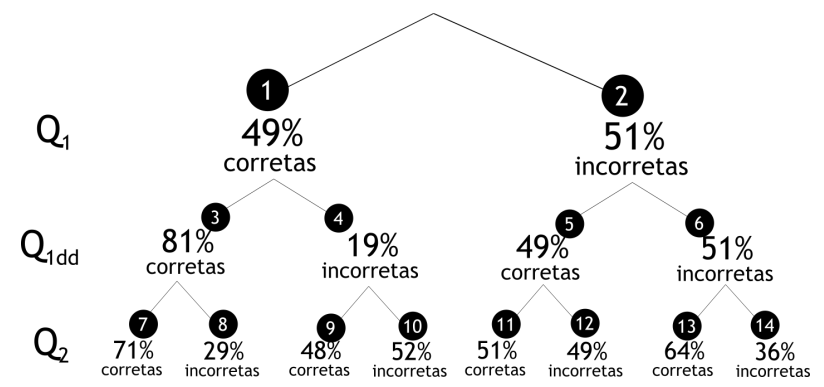

Figura 2: Diagrama com as porcentagens média de respostas corretas e incorretas dos conjuntos de questões $Q_{1}, Q_{1 d d}$ e $Q_{2}$ na disciplina de Lógica para Ciência da Computação na Universidade Federal de Jataí.

Evidência 2: Não é realizada uma "cópia cega" das respostas no momento de discussão entre os colegas.

Em [35], esta proposição é enunciada a partir do recorte proposto pelos autores. As porcentagens média referentes aos conjuntos $Q_{1 d d}$ e $Q_{2}$ (ver Evidência 1) estão bastante próximas. O que nos leva a admitir que de fato a compreensão do conceito não se dá minimamente pela "cópia cega" da resposta do colega na etapa de discussão em grupo. Se assim fosse, é bem possível que os valores de $Q_{2}$ estivessem mais próximos de $Q_{1}$ (o que não é verdade). A justificação mais plausível para estes valores, dado que $q_{1}$ e $q_{2}$ são isomórficas (i.e. não são iguais), é que na etapa de discussão entre os colegas existe um ganho de aprendizagem efetivo.

É fato que nas porcentagens apresentadas na Evidência 1 há um equilíbrio dinâmico, de forma que aqueles que acertaram em $Q_{1 d d}$ não necessariamente acertaram $Q_{2}$ (ver Figura 2). Por exemplo, aproximadamente $23,75 \%$ (Nós 8 e 12) dos que responderam corretamente $Q_{1 d d}$, responderam incorretamente $Q_{2}$, ocorrendo assim um "fluxo negativo". Entretanto, aproximadamente 20, 88\% (Nós 9 e 13) dos que responderam incorretamente $Q_{1 d d}$, responderam corretamente $Q_{2}$, ocorrendo assim um "fluxo positivo". Desta forma, a diferença $20,88 \%-23,75 \% \cong-2,87 \%$ justifica a pequena diferença entre as porcentagens média de $Q_{2}$ e $Q_{1 d d}$, embora o fluxo de um para o outro tenha sido considerável.

Evidência 3: A discussão entre colegas pode promover um ganho de aprendizagem.

Constata-se, a partir da análise dos dados D3, indícios de que a discussão entre colegas promove um ganho de aprendizagem. 
Sócrates ${ }^{3}$ afirma "[...] que quando estávamos conversando sobre as respostas dadas, muitas vezes tínhamos que convencer (ensinar) o outro colega e assim o conhecimento acabava fixando melhor na minha cabeça”. Este tipo de retorno também esteve presente em respostas de outros estudantes, como na fala de Platão: "A interação dos alunos durante a discussão facilitou a aprendizagem".

Esta leitura é condizente com a análise dos dados D2, sobre as impressões dos estudantes em termos quantitativos. A asserção QT1.3 enunciou que "discutir sobre o assunto com os meus colegas em sala ajudou-me a compreender melhor o material exigido no estudo prévio”. Esta asserção apresentou $67 \%$ de concordância plena com o $\operatorname{IndRep}(Q T 1.3)=88,89 \%$.

Evidência 4: O retorno imediato garante condições favoráveis para que a aprendizagem ocorra.

Constata-se, a partir da análise dos dados D3, indícios de que o retorno imediato garante condições favoráveis para que a aprendizagem ocorra. Aristóteles afirma o seguinte:

"Não consigo ver uma maneira mais eficaz para ministrar a matéria de Lógica para Ciência da Computação, ver diretamente e rapidamente nossos erros, através das perguntas e respostas pelo QR Code, foi simplesmente muito importante (para mim pelo menos) para o entendimento da matéria".

Este tipo de retorno também esteve presente em respostas de outros estudantes, como na fala de Diógenes: "[A PI] estimula o aluno a participar melhor da aula podendo ter um rendimento melhor e já saber como está seu nível de conhecimento na disciplina”.

Algo interessante foi encontrado na fala de Nicômaco que afirma a necessidade de trabalhar "[...] exercícios com os alunos para diagnosticar os pontos fortes e fracos, para então remedia-los, tal qual foi feito". A sensação é de que ele ao mesmo tempo percebe que a avaliação diagnóstica foi realizada através da PI ("[...] tal qual foi feito") e expressa o desejo de que ela seja mais explorada em outros espaços de aprendizagem.

Esta leitura é condizente com a análise dos dados D2. A asserção QT1.4 enunciou que "o retorno imediato da votação ajudou-me a focar nas fragilidades da minha compreensão sobre o material da disciplina”. Esta asserção apresentou $72 \%$ de concordância plena com o IndRep $(Q T 1.4)=90,28 \%$.

Evidência 5: A exposição ao contraditório possibilita uma validação em tempo real da suposta aprendizagem ocorrida.

Constata-se, a partir da análise dos dados D3, indícios de que esta evidência seja verdade. Sófocles afirma que o "[...] fato de ter opiniões diversas do seus colega de classe" foi o que ele mais gostou neste formato de aula.

Entretanto, esteve presente também um sentimento de inadequação desta etapa da PI. Utilizar as respostas das perguntas em sala de aula como parte da pontuação necessária para fins de aprovação ou reprovação parece não ter sido uma boa decisão para esta turma. Disse assim Afrodite:

"Às vezes, uma boa argumentação de um colega pode levar a uma resposta errada, e avaliar as respostas dos exercícios dados em aula pode prejudicar duplamente

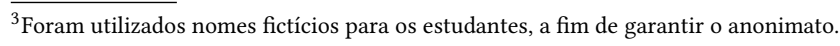

alguém que perdeu a aula, ou que ainda precisa de mais tempo para absorver o conteúdo".

Logo, realizar a avaliação de controle a partir da votação de questões no PI levou alguns estudantes a ter a opinião de que a exposição ao contraditório pode ter consequências negativas para a aprendizagem.

Ainda neste sentido, Tales afirmou que "o fato de acertar de primeira, mas, tirando a dúvida com os colegas, errar na segunda tentativa" foi o que ele detestou na PI. A exposição ao contraditório deveria ser uma necessidade natural do aprendiz, desejoso pelo conhecimento. Entretanto, a sensação ainda é de que a perda da pontuação, devido ao erro (respostas incorretas), é recebida pelo estudante mais como uma punição do que como uma oportunidade de evolução.

Evidência 6: A dinamicidade da abordagem contribui positivamente na concentração dos estudantes em sala de aula.

Constata-se, a partir da análise dos dados D3, indícios de que esta evidência seja verdade. Anaximandro afirma que " a dinamicidade não deixa com que os alunos se percam facilmente durante a aula e, consequentemente, a chance de êxito nos estudos e provas tende a aumentar para cada aluno". Assim, para ele, a dinamicidade contribui como um dos elementos favoráveis para uma boa aprendizagem.

Ainda nesta direção, ao ser perguntado sobre o que mudaria neste formato de aula, Pitágoras diz que "buscaria uma forma dinâmica e não entediante, acredito que o modo tradicional de aula não se encaixa para lógica”. Para ele, a dinâmica contribui para que a aula não fique entediante, o que certamente favorece positivamente na concentração dos estudantes em sala.

Apesar da aula ser percebida como dinâmica, para alguns, Anaxímenes registra a ocorrência de falta de concentração de alguns. Diz ele que "às vezes, alguns colegas apenas brincavam ou conversavam sobre coisas aleatórias nos momentos de discussão". Um caminho de resolução para este problema é o rodízio dos alunos entre os grupos em cada aula. Entretanto, na maioria das vezes, a estratégia de proximidade do estudantes foi a opção utilizada.

Evidência 7: A estrutura da PI traz elementos de gamificação que envolvem os estudantes de Computação na disciplina”.

Os estudantes de Computação, de uma forma geral, têm um certo apreço aos jogos digitais. Isto, de uma certa forma, leva os estudantes a serem mais simpáticos a metodologias que incluam elementos de gamificação. Sobre de que forma você ministraria esta disciplina, Heráclito afirma que seria bom haver "[...] gincanas entre grupos sobre o assunto de Lógica. trabalhos em grupos com temas propostos pelo professor! Palestras! Provas e tarefas?".

Ainda neste sentido, Parmênides diz que seria interessante uma “competição no número de questões acertadas com prêmio para os três [primeiros] colocados (uma semana de RU [Restaurante Universitário], por exemplo)". É possível extrair a associação implícita da gamificação com a dinamicidade (Evidência 6) e a imersão na atividade em questão.

Também há a crença de que a gamificação força, talvez naturalmente, uma maior participação dos estudantes. Diz Plotino que "tentaria acrescentar mais disputas entre os alunos, para tentar fazer o grupo de discussão ser levado mais a sério. Talvez os integrantes do grupo deveriam ser aleatórios toda aula". É bem possível que ele 
esteja também querendo promover um ambiente mais favorável, conforme apontado por Anaxímenes (Evidência 6).

É fato que quanto maior forem as mudanças necessárias para que o professor altere a dinâmica da aula, maior será o ônus que este terá que arcar em relação ao planejamento de sua aula. O desejo de tornar a aula mais dinâmica com o propósito de provocar um maior engajamento com a descoberta do conhecimento é compartilhado tanto por professores quanto por alunos. Entretanto, é necessário construir um ambiente acadêmico favorável para que estas mudanças possam ser viabilizadas na prática.

\subsection{Receptividade da PI (P2)}

A P2 afirma que a PI é bem recebida pelos alunos. A seguir, iremos trazer os resultados da investigação de tal afirmação.

Evidência 8: Os alunos indicariam a abordagem para outros professores.

Constata-se, a partir da análise dos dados D3, indícios de que esta evidência seja verdade. Demócrito afirma que

"O método em si é incrível, e eu concordo que deveria ser usado em mais matérias, pois facilita o aprendizado e acaba visando uma homogeneidade da base de compreensão da turma. A única parte que deixa insegurança, é a questão psicológica do método de avaliação".

Percebe-se, que assim, a receptividade da abordagem é positiva, embora o método de avaliação tenha sido uma fonte de insegurança, conforme aponta o aluno. É bem possível que este problema esteja associado com a pontuação relacionada às respostas dos alunos durante às discussões em grupo (conforme já apontado na Evidência $5)$.

Esta leitura é condizente com a análise dos dados D2. A asserção QT1.6 enunciou que "eu recomendo que outros professores utilizassem esta abordagem (estudo prévio, questões conceituais, votações, discussão em grupo) em suas disciplinas”. Esta asserção apresentou $67 \%$ de concordância plena com o IndRep $(Q T 1.6)=83,33 \%$.

Evidência 9: $\mathrm{O}$ uso da tecnologia favoreceu positivamente à aprovação da abordagem.

O uso da tecnologia favorece positivamente em várias direções. Para a PI, dentre outros motivos, ele é importante para (i) imprimir uma maior velocidade na obtenção do retorno imediato para os alunos (Evidência 4), (ii) promover um ambiente mais favorável à concentração dos alunos (Evidência 6), e (iii) trazer elementos de gamificação que envolvem os estudantes na sala de aula (Evidência 7).

Esta leitura é condizente com a análise dos dados D2. A asserção QT1.5 enunciou que "as placas (QR Codes), utilizadas para a realização da votação, são ferramentas de colaboração fáceis de usar”. Esta asserção apresentou 83\% de concordância plena com o IndRep $(Q T 1.5)=93,75 \%$ (o maior índice de todo o questionário).

Em uma outra direção, foi constatado que o "registro das respostas individuais dos estudantes", como disse um aluno, é um dos problemas da abordagem. Embora a fala do estudante não esteja claro, é bem possível que este seu incômodo esteja associado com os problemas de avaliação citados nas Evidências 5 e 8.

Ainda foi registrada, por alguns alunos, a falta de agilidade na entrega das placas no início de cada aula. Diz assim Euclides, "eu acho que a entrega dos cartões com códigos $Q R$ poderia ser agilizada, mas não possuo uma sugestão imediata”. E Górgias reforça, "antes da aula começar, os alunos já deveriam ter a placa em mãos”.

No início de cada encontro, a entrega das placas de QR Code demorava em torno de 15 minutos para ser realizada. A configuração da sala de aula, junto com a distribuição das placas, variava entre 20 a 30 minutos a cada encontro. Cada encontro durava uma hora e meia. Apesar de ser necessário repensar este cenário com o propósito de mitigar estes incômodos, o custo de adaptação de uma sala comum para a PI compensa no cômputo geral.

Evidência 10: A escolha do material para a realização dos estudos prévios dos estudantes foi satisfatória.

Durante a ministração da disciplina, surgiu uma suspeita, por parte do professor, se o nível de dificuldade do material proposto estava ou não adequado. Tendo em vista esta indagação, tornouse necessária a inclusão da asserção QT1.1 para levantar dados específicos com o propósito de investigá-la melhor.

Desta forma, a asserção QT1.1 enunciou que "o nível de dificuldade do material proposto nos estudos prévios foram satisfatórios para mim". Esta asserção obteve quase a metade dos estudantes indicando concordância plena (47\%), com o $\operatorname{IndRep}(Q T 1.1)=80,56 \%$. Percebe-se assim que a dificuldade do material proposto estava em um nível satisfatório para a turma.

Ainda nesta direção, a asserção QT1.2 enunciou que "pensar sozinho sobre as questões apresentadas em sala de aula, antes de discutir com os meus colegas, ajudou-me a aprender sobre o material exigido no estudo prévio". Esta asserção obteve bem mais da metade dos estudantes indicando concordância plena (67\%), com o IndRep $(Q T 1.2)=84,03 \%$. Este indício reforça, indiretamente, que a escolha do material proposto foi adequada para a turma de forma que, durante a etapa de votação individual, foi permitido um momento de aprendizagem significativa.

Entretanto, foi possível identificar nas falas de algum estudantes, a objeção de que "[...] o livro é de difícil entendimento". Ainda neste sentido, Dionísio afirmou que, se ministrasse a disciplina, "[...] passaria um livro com uma linguagem de fácil aprendizagem". $\mathrm{O}$ livro utilizado lança mão de um formalismo matemático mediano, quando comparado a outros livros de lógica adotados em outras instituições.

É interessante perceber, ainda em relação a este ponto, o que a estudante Atena declarou. Diz ela que "normalmente os textos que eram solicitados para serem lidos eram muito confusos. Porém, após a aula, eles se tornavam bem mais simples para interpretar". Este é mais um indício de que a aprendizagem de fato ocorria a partir do material proposto, apesar de todas as ressalvas mencionadas pelos estudantes.

É possível que a dificuldade encontrada pelos alunos deva-se a fragilidades da formação destes durante o ensino básico. A declaração de Leucipo contribui com este raciocínio:

"Para poder participar desta metodologia o aluno precisa ter uma bagagem de conhecimento razoável, mas nem sempre todos têm. Então é preciso ir atrás, contudo nem todos sabem muito bem como fazer/conseguir essa bagagem pela forma que os instrumentos de aprendizagem são feitos, como os textos que tínhamos que ler 
para adquirir algum conhecimento, as vezes só conseguia entender algo quando já tinha se passado umas 2-3 aulas depois que o professor explicava as questões dadas".

Evidência 11: Houve um retorno positivo da turma em relação às todas as etapas do ciclo da PI.

Os dados coletados D2 são referentes a todas as etapas do ciclo da PI. Conforme é possível verificar na Tabela 1, o índice de representatividade de todas as perguntas foram superior a $80 \%$, de forma que a média geral destes resultados foi de $86,81 \%$. Desta forma, a partir destes indicadores, é possível afirmar que a turma respondeu positivamente à abordagem.

Ainda nesta direção, quando perguntados sobre "o que você mudaria, se pudesse, no formato da aula?” (QT2.4), houve vários retornos genéricos do tipo "faria do jeito que você fez" ou "não teve nada que não gostei”. Isto pode refletir um pensamento acrítico sobre o processo ou, talvez, uma boa receptividade da abordagem utilizada (conforme aponta outras evidências), ou quem sabe um pouco de ambos. Diante das demais evidências e das outras falas aqui mencionadas, é mais provável que haja, na realidade, uma disposição favorável ao uso da abordagem.

É importante ressaltar algumas falas de estudantes sobre a não adesão integral do professor em relação à abordagem. A proposta original do PI admite uma sequência específica. Entretanto, o professor omitiu o primeiro momento da explanação e fez a exposição direta da questão aos alunos. A explanação era realizada posteriormente às votações realizadas. Sobre como ministraria as aulas desta disciplina, Sêneca disse

"Faria o mesmo, mas também revisaria o conteúdo de forma breve (5 minutos seriam o suficiente), atendendo alguma dúvida gritante ou generalizada que pudesse desandar o desempenho durante a aula em si".

Diz também Agostinho que seria interessante "uma breve explicação (resumão) sobre os conteúdos (para que eles servem), despertando o interesse nos alunos para eles pesquisarem mais a fundo sobre o conteúdo ministrado [...]".

A fase inicial de exposição dialogada, no início do ciclo, é prevista na proposta original da PI. A escolha do professor de realizar o reposicionamento desta fase residiu no intento de provocar a necessidade no aluno de investigar mais a fundo sobre a questão apresentada. Uma vez que as votações foram realizadas e os estudantes recebiam o retorno da porcentagem de respostas corretas, surgiria uma curiosidade natural no aprendiz em compreender as razões do por quê aquela questão precisasse ser melhor respondida de uma certa forma ao detrimento de outra.

É bem possível que esta preocupação, com a inversão desta etapa, também esteja associada com o seu desempenho, em termos de pontuação, na votação. A necessidade torna-se mais imperiosa, em não ter certos tipos de dúvidas antes das perguntas, quando o estudante sente-se prejudicado na pontuação referente à sua avaliação. Esta leitura é coerente com exposto sobre a avaliação das respostas em sala nas explanações das Evidências 5, 8 e 9.

Apesar da evidência apontar fortemente para o retorno positivo da turma em relação à PI, existe algumas falas indicando uma resistência à aprendizagem ativa. Helena afirma que a PI não deveria “[...] ocupar a aula inteira. Nós aprendíamos todo o conteúdo fora da aula, lendo os textos". Parece que para Helena, o professor cumpre a sua função de ensinar mais adequadamente expondo o conteúdo do que configurando apropriadamente as condições para que a aprendizagem ocorra. Confirmando esta suspeita, Ulisses afirma que percebia a "falta do professor em sala de aula" e Édipo declara que "a dinâmica ocupa muito tempo, desde a organização. Eu ministraria o conteúdo em aula e faria a dinâmica online”.

A PI, como metodologia ativa, ainda é vista (por alguns) como uma dinâmica que é interessante, mas não é o ensino propriamente dito. Embora que a percepção geral do uso da PI foi bastante favorável, ainda é presente este sentimento em alguns. É possível que seja fruto da forte mudança de paradigma que a metodologias ativas impõe tanto para o aprendiz quanto para o docente.

Apolo também menciona o seu receio em relação à sobrecarga das atividades se os demais professores adotassem esta mesma estratégia. Diz ele que "caso os demais professores exigissem estudo prévio do material para assistir às aulas, isso somaria às tarefas e trabalho de faculdade dos alunos e demandaria muito tempo". Diante de um cenário de competitividade e bastante cobrança, a aprendizagem ativa pode ter uma certa rejeição, dependendo do nível de exigência que ela exija dos estudantes.

\subsection{Questões Indiretas à PI}

Duas questões indiretas, durante a utilização da PI, são importantes de ser mencionadas. Estas questões são apresentadas a seguir.

A primeira questão diz respeito aos critérios de avaliação utilizados durante a disciplina. Como parte da avaliação de controle, $30 \%$ da pontuação obtida pelos alunos era oriunda das respostas dadas por eles em sala de aula, colhidas da votação da PI. As votações antes e depois da discussão eram pontuadas, se respondidas corretamente, com o mesmo peso. Se acertassem a todas as questões da PI em sala, os estudantes recebiam a pontuação completa. Caso contrário, a pontuação era proporcional ao número de acertos.

Se ministrasse a disciplina, Homero diz que mudaria

“[...] o fato das perguntas em sala valer muita
nota. Pois mesmo que defenda a causa de 'se não
valer nota, os alunos não prestam atenção', é
muito mais difícil do que até uma prova. Pois
tem pouco tempo para resposta e não tem o foco
suficiente, resultando na maioria da sala tiraram
nota abaixo nesta área".

Esta insatisfação sobre a avaliação das respostas da PI foram mencionadas nas Evidências 5, 8, 9 e 12. Percebeu-se, posteriormente, que esta escolha não foi adequada. Como alternativa, a pontuação poderia ser colocada como uma bonificação à nota final da disciplina, ou simplesmente não ter sido colocada nenhuma pontuação para fins de controle a estas respostas.

A questão da avaliação vai além do uso ou não da PI em sala de aula. Evoca sentimentos de frustração e até rejeição, não colaborando para um ambiente favorável à aprendizagem. Baco faz uma declaração nesta direção:

"Alguns alunos já comentaram, em conversas sobre a aula, que se sentiam frustrados e/ou pressionados, pois mesmo estudando e até sabendo da matéria, não conseguiam os resultados antecipados, por insegurança ou estresse. Contudo, isso 


\begin{tabular}{c|c|c|c|c|c|c|c}
\hline Pergunta & QT1.1 & QT1.2 & QT1.3 & QT1.4 & QT1.5 & QT1.6 & Geral \\
\hline IndRep $(P)$ & $80,56 \%$ & $84,03 \%$ & $88,89 \%$ & $90,28 \%$ & $93,75 \%$ & $83,33 \%$ & $86,81 \%$ \\
\hline
\end{tabular}

Tabela 1: Índice de representatividade de todas as perguntas do Questionário 1, incluindo a média geral delas.

\begin{abstract}
não chega a ser uma falha do sistema, mas sim da própria natureza dos alunos. Algo que ajudaria, porém, é uma abordagem que vise, em primeira exposição, 'confortar' o aluno no ambiente em que ele está sendo exposto, para que possa ficar confortável com o uso do material proposto, ao contrário de pressionado pela consequência do seu uso".
\end{abstract}

A outra questão importante foi a necessidade de o professor da disciplina ser submetido a uma cirurgia. Devido a esta realidade, a organização das aulas durante o semestre foi afetada e a quantidade de aulas semanais aumentou de duas para três.

Neste sentido, Tobias afirmou que "disponibilizaria duas aula por semana" apenas. Também foi dito por Cícero que "o tempo de ensino [...] passa muito rápido. Mal aprende um já tem que aprender outro". Talvez a sensação destes alunos fossem diferente se não houvesse o afastamento por razões médicas do professor.

\subsection{Ameaças à Validade dos Resultados}

É pertinente ressaltar que o fluxo da exposição das questões isomórficas não se seguiu identicamente ao realizado em [28]. No processo realizado pelos autores, a votação individual de $q_{2}$ é realizada imediatamente após a votação de $q_{1 d d}$ (pós-discussão entre colegas). Um dos propósitos nesta abordagem é replicar mais fidedignamente o percurso metodológico apresentado em [35], objetivando garantir uma menor influência do docente nos resultados relativos ao ganho de aprendizagem do aluno.

Este trabalho seguiu o fluxo original da PI, havendo apenas a inversão da etapa da exposição dialogada (ver Evidência 11). Logo, após a votação individual de $q_{1 d d}$ é realizada a exposição dialogada e, logo após, apresentada $q_{2}$. O professor da disciplina adotou este caminho metodológico por julgar ser o mais natural no processo de inquirição / investigação dos estudantes, promovendo uma curiosidade imediata no momento em que as possíveis dúvidas vão surgindo.

Este registro é importante na eventual comparação direta entre os resultados deste trabalho com os obtidos em [28]. Estas ressalvas necessitam ser feitas com o propósito de se compreender adequadamente o contexto envolvido nos dois projetos.

Também é importante registrar que a força das evidências apresentadas neste trabalho pode ser melhor explorada em futuros estudos de casos. Relações de causalidade a partir de grupos de controle podem fornecer indícios mais sólidos para servir de suporte para as proposições apresentadas.

\section{TRABALHOS RELACIONADOS}

Na Educação de Computação, a PI vem sido utilizada em vários contextos como no Ensino Médio [38], e no Ensino Técnico [25, 26]. Entretanto nenhum destes trabalhos investigam o uso da PI no nível superior. Na Educação Superior de Computação no Brasil, existem investigações sobre o uso da PI no ensino de Linguagens Formais e Autômatos [31], Lógica de Programação [7] e Interação Homem-Máquina [11]. Porém nenhum destes trabalhos investigam o uso da PI na disciplina de Lógica para Computação. Também há trabalhos que investigam o uso da PI em contextos fora da América do Sul $[6,17,19,28]$. Todavia, o recorte deste trabalho é o uso da PI na Educação Superior de Computação no Brasil.

\section{CONSIDERAÇÕES FINAIS}

O objetivo desta pesquisa foi discutir o impacto do uso da PI na Educação de Computação no Brasil no ensino de Lógica para Computação. Duas questões de estudo foram elencadas. A primeira questão foi "Por que a utilização da PI é adequada para a Educação de Computação no Brasil?”. E a segunda questão foi “Como são as impressões dos estudantes em relação à PI?”. O contexto da pesquisa foi a turma do Bacharelado em Ciência da Computação de 2018.1 da Universidade Federal de Jataí.

Foram constatadas evidências suficientes para a veracidade de duas proposições a respeito destas questões de estudo. A primeira proposição é "A utilização da PI garante um ganho de aprendizagem dos alunos". A segunda proposição é "A PI é bem recebida pelos alunos". Conclui-se, desta forma, que a PI é adequada para a Educação Superior de Computação no Brasil e que os estudantes recebem positivamente a utilização da abordagem em sala de aula.

Como mencionado na discussão dos resultados, um dos pontos de maior insatisfação, por parte dos estudantes, foram questões relacionadas à avaliação de controle. A utilização das respostas das votações utilizadas em sala durante a PI como parte da pontuação da disciplina não foi bem recebida pelos estudantes. É necessário atentar-se a este retorno dos estudantes, pois é bem possível que os efeitos positivos evidenciados nos resultados pudessem ser bem mais expressivos.

Como trabalho futuro, surge naturalmente a necessidade de estender a natureza deste experimento para outros casos reveladores no contexto da Educação de Computação na América do Sul. Também é interessante ressaltar a porcentagem média expressa no Nó 13 (Figura 2). Apesar destes estudantes terem respondidos incorretamente tanto $q_{1}$ quanto $q_{1 d d}, 64 \%$ deles responderam corretamente $q_{2}$. Seria pertinente investigar mais a fundo para identificar os motivos pelos quais tal fato ocorreu.

\section{REFERÊNCIAS}

[1] Ives Solano Araujo and Eric Mazur. 2013. Instrução pelos colegas e ensino sob medida: uma proposta para o engajamento dos alunos no processo de ensinoaprendizagem de Física. Caderno brasileiro de ensino de física. Florianópolis. Vol. 30, n. 2 (ago. 2013), p. 362-384 (2013).

[2] David Paul Ausubel. 2000. Preview of Assimilation Theory of Meaningful Learning and Retention. In The acquisition and retention of knowledge: A cognitive view. Springer Science \& Business Media, 01-18.

[3] Ali Günay Balım. 2009. The Effects of Discovery Learning on Students' Success and Inquiry Learning Skills. Eurasian fournal of Educational Research (EFER) 35 (2009), 1-20.

[4] Leland Beck and Alexander Chizhik. 2013. Cooperative learning instructional methods for CS1: Design, implementation, and evaluation. ACM Transactions on 
Computing Education (TOCE) 13 (2013), 10. Issue 3.

[5] Charles C Bonwell and James A Eison. 1991. Active Learning: Creating Excitement in the Classroom. ASHE-ERIC Higher Education Reports.

[6] Joe D Chase and Edward G Okie. 2000. Combining cooperative learning and peer instruction in introductory computer science. In ACM SIGCSE Bulletin, Vol. 32. ACM, 372-376.

[7] Patricia Mariotto Mozzaquatro Chicon, Cindia Rosa Toniazzo Quaresma, and Solange Beatriz Billig Garcês. 2018. Aplicação do Método de ensino Peer Instruction para o Ensino de Lógica de Programação com acadêmicos do Curso de Ciência da Computação. In Anais do $5^{\circ}$ SENID (Seminário Nacional de Inclusão Digital)- Cultura Digital na Educação.

[8] C. H. Crouch and E. Mazur. 2001. Peer Instruction: Ten years of experience and results. American fournal of Physics 69, 9 (2001), 970-977.

[9] John Dewey. 2004. Democracy and education. Courier Corporation.

[10] Sally Fincher and Marian Petre. 2004. Mapping the territory. Computer science education research (2004).

[11] Fabrício M Gonçalves, Alessandro Arpetti, and M Cecília C Baranauskas. 2014. Facilitando a construção social de significado em sistemas de aprendizado colaborativo. In Proceedings of the XIX international workshop on educational software, TISE, Vol. 10. 318-326.

[12] Scott Grissom. 2013. Introduction to special issue on alternatives to lecture in the computer science classroom. ACM Transactions on Computing Education (TOCE) 13, 3 (2013), 9.

[13] Richard R Hake. 1998. Interactive-engagement versus traditional methods: A six-thousand-student survey of mechanics test data for introductory physics courses. American journal of Physics 66, 1 (1998), 64-74.

[14] David Hammer. 1995. Student inquiry in a physics class discussion. Cognition and Instruction 13, 3 (1995), 401-430.

[15] David Hammer. 1997. Discovery learning and discovery teaching. Cognition and instruction 15, 4 (1997), 485-529.

[16] Christian Holmboe, Linda McIver, and Carlisle George. 2001. Research agenda for computer science education. In 13th Workshop of the Psychology of Programming Interest Group, Vol. 207223.

[17] William E Johnson, Allison Luzader, Irfan Ahmed, Vassil Roussev, Golden G Richard III, and Cynthia B Lee. 2016. Development of Peer Instruction Questions for Cybersecurity Education. In 2016 USENIX Workshop on Advances in Security Education (ASE 16). USENIX Association.

[18] Kenneth Kotovsky, John R Hayes, and Herbert A Simon. 1985. Why are some problems hard? Evidence from Tower of Hanoi. Cognitive psychology 17, 2 (1985), 248-294.

[19] Cynthia Bailey Lee, Saturnino Garcia, and Leo Porter. 2013. Can Peer Instruction Be Effective in Upper-division Computer Science Courses? Trans. Comput. Educ. 13, 3, Article 12 (Aug. 2013), 22 pages. https://doi.org/10.1145/2499947.2499949

[20] E. Mazur. 1997. Peer Instruction: a User's Manual. Upper Saddle River, NJ: Prentice Hall.

[21] Maria da Graça Nicoletti Mizukami. 1986. Abordagem Tradicional. Editora Pedagógica e Universitária (EPU), Chapter 1, 7-18.

[22] Richard S. Moog and James N. Spencer. 2008. POGIL: An Overview. Chapter 1, 1-13. https://doi.org/10.1021/bk-2008-0994.ch001 arXiv:http://pubs.acs.org/doi/pdf/10.1021/bk-2008-0994.ch001

[23] Maykon Gonçalves Müller, Ives Solano Araujo, Eliane Angela Veit, and Julie Schell. 2017. Uma revisão da literatura acerca da implementação da metodologia interativa de ensino Peer Instruction (1991 a 2015). Revista brasileira de ensino de física. São Paulo. Vol. 39, n. 3 (jul./set. 2017), e3403, 20 p. (2017).

[24] Tomoko Nemoto and David Beglar. 2014. Developing Likert-scale questionnaires. In JALT 2013 Conference Proceedings. 1-8.

[25] Keila de Fátima Chagas Nogueira and Kenedy Lopes Nogueira. 2018. Aplicação de Metodologias Ativas utilizando Tecnologia Educacional. In CEUR Workhop
Proceedings, Vol. 2185. 530-535.

[26] Maria Angélica Figueiredo Oliveira, José Valdeni de Lima, Alberto Bastos do Canto Filho, Felipe Becker Nunes, Luciana V Lourega, and Jorge Nazareno Batista Melo. 2017. Aplicação do método Peer Instruction no ensino de Algoritmos e programação de computadores. RENOTE 15, 1 (2017).

[27] Leo Porter, Cynthia Bailey Lee, and Beth Simon. 2013. Halving fail rates using peer instruction: a study of four computer science courses. In Proceeding of the 44th ACM technical symposium on Computer science education. ACM, 177-182.

[28] L. Porter, C. Bailey Lee, B. Simon, and D. Zingaro. 2011. Peer Instruction: do students really learn from peer discussion in computing?. In Proceedings of the Seventh International Workshop on Computing Education Research. ACM, 45-52.

[29] Leo Porter, Dennis Bouvier, Quintin Cutts, Scott Grissom, Cynthia Lee, Robert McCartney, Daniel Zingaro, and Beth Simon. 2016. A Multi-institutional Study of Peer Instruction in Introductory Computing. ACM Inroads 7, 2 (May 2016), 76-81. https://doi.org/10.1145/2938142

[30] Anthony Robins. 2015. The ongoing challenges of computer science education research. Computer Science Education 25, 2 (2015), 115-119. https://doi.org/10.1080/ 08993408.2015.1034350 arXiv:http://dx.doi.org/10.1080/08993408.2015.1034350

[31] Luis Menasché Schechter and Luziane F de Mendonça. 2017. Uma Aplicação da Metodologia de "Sala de Aula Invertida" no Bacharelado em Ciência da Computação da UFRJ. Proceeding Series of the Brazilian Society of Computational and Applied Mathematics 5, 1 (2017).

[32] Prateek Shekhar, Matt Demonbrun, Maura Borrego, Cynthia Finelli, Michael Prince, Charles Henderson, and Cynthia Waters. 2015. Development of an observation protocol to study undergraduate engineering student resistance to active learning. International fournal of Engineering Education 31, 2 (2015), 597-609.

[33] Beth Simon, Michael Kohanfars, Jeff Lee, Karen Tamayo, and Quintin Cutts. 2010. Experience report: peer instruction in introductory computing. In Proceedings of the 41st ACM technical symposium on Computer science education. ACM, 341-345.

[34] Beth Simon, Julian Parris, and Jaime Spacco. 2013. How We Teach Impacts Student Learning: Peer Instruction vs. Lecture in CS0. In Proceeding of the 44th ACM Technical Symposium on Computer Science Education (Denver, Colorado, USA) (SIGCSE '13). ACM, New York, NY, USA, 41-46. https://doi.org/10.1145/ 2445196.2445215

[35] Michelle K Smith, William B Wood, Wendy K Adams, Carl Wieman, Jennifer K Knight, Nancy Guild, and Tin Tin Su. 2009. Why peer discussion improves student performance on in-class concept questions. Science 323, 5910 (2009), $122-124$.

[36] Michelle K Smith, William B Wood, Ken Krauter, and Jennifer K Knight. 2011. Combining peer discussion with instructor explanation increases student learning from in-class concept questions. CBE-Life Sciences Education 10, 1 (2011), 55-63.

[37] R. J. Sternberg and K. Sternberg. 2017. Introdução à Psicologia Cognitiva. In Psicologia Cognitiva (7 $7^{a}$ edição ed.). Cengage Learning, 02-31.

[38] Katiuscia Costa Barros Teixeira and Francisca Cláudia Fernandes Fontenele. 2017. Metodologia peer instruction no ensino de matrizes: um relato de experiência na disciplina de álgebra linear. EDUCAÇÃO MATEMÁTICA EM REVISTA-RS 1, 18 (2017).

[39] Trisha Vickrey, Kaitlyn Rosploch, Reihaneh Rahmanian, Matthew Pilarz, and Marilyne Stains. 2015. Research-Based Implementation of Peer Instruction: A literature review. CBE-Life Sciences Education 14, 1 (2015), es3.

[40] Robert K Yin. 2001. Estudo de Caso: Planejamento e Métodos. Bookman editora.

[41] Daniel Zingaro. 2010. Experience Report: Peer Instruction in Remedial Computer Science. In EdMedia: World Conference on Educational Media and Technology, Vol. 2010. 5030-5035.

[42] Daniel Zingaro and Leo Porter. 2014. Peer Instruction in computing: The value of instructor intervention. Computers \& Education 71 (2014), 87 - 96. https: //doi.org/10.1016/j.compedu.2013.09.015 